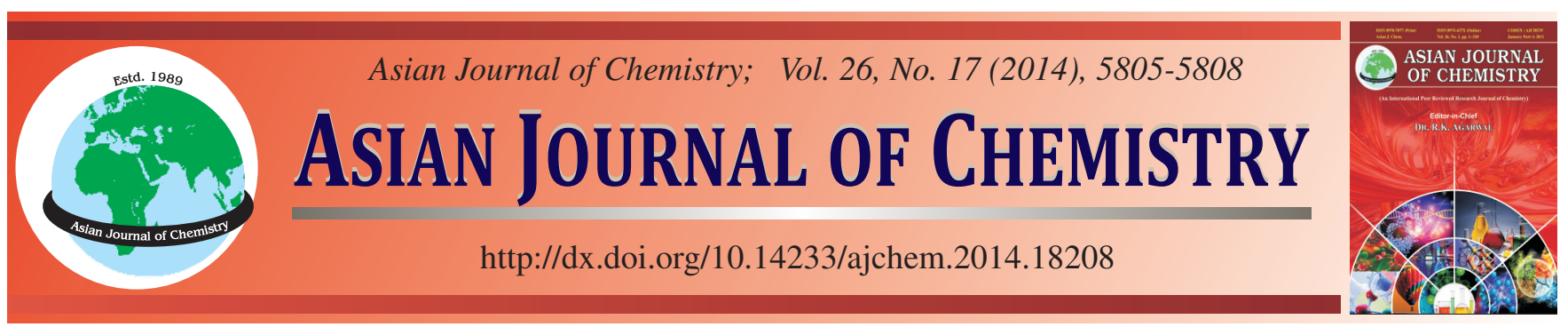

\title{
A New Two-Dimensional Silver Coordination Polymer Constructed by 1,3-Bis(4-pyridyl)propane and 2,6-Dichlorophenylacetic Acid: Synthesis, Structure, Luminescence and Thermal Stable Properties $\dagger$
}

\author{
XiaO-Min HaO ${ }^{1,2}$, Gang Chen ${ }^{1, *}$ and Chang-Sheng Gu ${ }^{2, *}$
}

${ }^{1}$ Department of Chemistry, Harbin Institute of Technology, Harbin, P.R. China

${ }^{2}$ Department of Applied Chemistry, Guangdong Ocean University, Zhanjiang, P.R. China

*Corresponding author: E-mail: gchen@hit.edu.cn; gcsheng1968@126.com

\begin{abstract}
A novel complex 1 of $\left\{[\mathrm{Ag}(\mathrm{bpp})(\mathrm{dcpa})] \mathrm{H}_{2} \mathrm{O}\right\}_{\mathrm{n}}$ [Hdcpa: 2,6-dichlorophenylacetic acid; bpp: 1,3-bis(4-pyridyl)propane] was synthesized and characterized by elemental analysis, IR, TGA, X-ray single crystal diffraction. The carboxylate oxygens of the Hdcpa ligands connect one $\operatorname{Ag}(\mathrm{I})$ ion in bidentate chelating mode to form mononuclear silver building blocks, which are into a 1D infinite chain through trans-bpp ligands. A two-dimensional network consist of adjacent Ag-bpp chain through Ag-Ag interaction. Furthermore, the luminescent property of complex 1 was investigated at room temperature. CCDC: 996495.
\end{abstract}

Keywords: Ag(I) coordinated polymer, Crystal structure, Luminesce.

\section{INTRODUCTION}

Inorganic-organic hybrid materials constructed from organic ligands and metal ions have attracted considerable attention for their variety of interesting architectures and beneficial properties such as porosity, catalysis, magnetism, luminescence, non-linear optics, etc. ${ }^{1-4}$. Currently, considerable efforts have been made to design and construct such compounds with desired structures and properties.Among them, tactical synthesis or selection of the organic ligand and controlling reaction condition are key factors for achieving expected hybrid materials ${ }^{5}$. Carboxylates can provide various coordination modes (monodentate and bis-monodentate), while pyridyl ligands can be used as a pillar or bridge to ligate metal nodes ${ }^{6,7}$. It is well known that the flexible 1,3-bis(4-pyridyl)propane (bpp) is an excellent candidate for constructing novel structures as the auxiliary ligands ${ }^{8-11}$. The aromatic carboxylate ligand of chlorophenylacetic acid to construct various coordination polymers may result in some tailorable structures ${ }^{12,13}$. So far, work on the construction of metals coordination polymers involving 2,6-dichlorophenylacetic acid (Hdcpa) and N-containing auxiliary ligands is still scarce. In this study, we introduced Hdcpa with the bpp ligand in order to assemble Ag(I) coordination polymer. In addition, thermal stability and luminescent property of polymer were measured.

\section{EXPERIMENTAL}

All chemicals purchased should be of reagent grade and used without further purification. Elemental analysis were performed on a CARLO ERBA 1106 analyzer. FT-IR spectra were recorded on a BRUKER EQUINOX 55 FT-IR spectrometer using $\mathrm{KBr}$ pellet at a resolution of $0.5 \mathrm{~cm}^{-1}$ (4000-400 $\mathrm{cm}^{-1}$ ). Luminescence spectra for crystal solid samples were recorded at room temperature on a Perkin Elmer LS 55 phosphorimeter.Thermogravimetry analyses were performed on an automatic simultaneous thermal analyzer (PE TG/DTA 6300) under a flow of $\mathrm{N}_{2}$ at a heating rate of $10{ }^{\circ} \mathrm{C} \mathrm{min}^{-1}$ between ambient temperature and $800{ }^{\circ} \mathrm{C}$.

General procedure: Complex 1 was prepared by the addition of stoichiometric amounts of silver nitrate $(0.069 \mathrm{~g}$, $0.5 \mathrm{mmol}), 2$,6-dichlorophenylacetic acid ( $0.1025 \mathrm{~g}, 0.5 \mathrm{mmol})$ and 1,3-bis(4-pyridyl)propane (0.0991 g, $0.5 \mathrm{mmol}$ ) dissolved in $1: 1$ methanol/water solution and the $\mathrm{pH}$ was adjusted to 7 with $0.1 \mathrm{M}$ potassium hydroxide solution. After the mixture was stirred for $0.5 \mathrm{~h}$, the precipitate was dissolved in the aqueous solution of ammonia (14 M) which was added drop by drop. Colourless crystals of compound were obtained by evaporation of the solution for 10 days at room temperature. Analysis calculated for $\mathrm{C}_{42} \mathrm{H}_{40} \mathrm{~N}_{4} \mathrm{O}_{5} \mathrm{Cl}_{4} \mathrm{Ag}_{2}$ : C 53.89, $\mathrm{H} 4.15$, N $5.60 \%$; found: C 51.09, H 3.90, N $5.42 \%$. IR ( KBr pellet, 


\begin{tabular}{cc|cc}
\hline \multicolumn{4}{c}{ TABLE-1 } \\
CRYSTAL DATA AND STRUCTURE REFINEMENTS OF COMPLEX 1 \\
\hline Empirical formula & $\mathrm{C}_{42} \mathrm{H}_{40} \mathrm{~N}_{4} \mathrm{O}_{5} \mathrm{Cl}_{4} \mathrm{Ag}_{2}$ & $\gamma\left({ }^{\circ}\right)$ & 90 \\
Formula weight & 1038.32 & $\mathrm{~V}\left(\AA^{3}\right)$ & $4264.9(17)$ \\
Temperature $(\mathrm{K})$ & $296(2)$ & $\mathrm{Z}$ & 4 \\
Size $(\mathrm{mm})$ & $0.30 \times 0.20 \times 0.18$ & $\mu\left(\mathrm{mm}^{-1}\right)$ & 1.217 \\
$\theta$ range for data collection $\left(^{\circ}\right)$ & $1.72-25.00$ & $\mathrm{D}_{\mathrm{c}}\left(\mathrm{g} \mathrm{cm}^{-3}\right)$ & 1.617 \\
Crystal system & Monoclinic & $\mathrm{F}_{(000)}$ & 2088 \\
Space group & $\mathrm{C} 2 / \mathrm{c}$ & Reflections collected & 11265 \\
$\mathrm{a}(\AA)$ & $25.477(6)$ & Independent reflections $\left(\mathrm{R}_{\text {int }}\right)$ & $3731(0.0230)$ \\
$\mathrm{b}(\AA)$ & Goodness of fit on $\mathrm{F}^{2}$ & 1.022 \\
$\mathrm{c}(\AA)$ & $\mathrm{R}_{1}, \mathrm{wR}^{2}(\mathrm{I}>2 \sigma(\mathrm{I}))$ & $0.0313,0.0796$ \\
$\alpha\left(^{\circ}\right)$ & $\mathrm{R}_{1}, \mathrm{wR}_{2}(\mathrm{all}$ data $)$ & $0.0382,0.0853$ \\
$\beta\left(^{\circ}\right)$ & $21.013(5)$ & $(\Delta \rho)_{\max },(\Delta \rho)_{\min } / \mathrm{e} \AA^{3}\left(\mathrm{e} \mathrm{nm}^{-3}\right)$ & $0.762,-0.728$ \\
\hline
\end{tabular}

$\left.\mathrm{cm}^{-1}\right)$ : 3403(w), 2940(w), 2373(w), 1610(s), 1584(s), 1556(m), 1527(w), 1496(w), 1435(m), 1364(m), 1266(w), 1215(w), 1156(w), 1156(w), 1140(w), 1078(w), 1007(w), 936(m), 904(w), 806(m), 771(m), 664(w), 509(w).

Detection method: A single crystal with dimensions of $0.30 \mathrm{~mm} \times 0.20 \mathrm{~mm} \times 0.18 \mathrm{~mm}$ was mounted on a glass fiber for data collection which was performed on a Bruker SMART APEXII CCD diffractometer operating at $50 \mathrm{kV}$ and $30 \mathrm{~mA}$ using a $\mathrm{MoK}_{\alpha}$ radiation $(\lambda=0.071073 \mathrm{~nm})$ at $295(2) \mathrm{K}$ by using a $\omega$ scan mode. In the range $1.72^{\circ} \leq \theta \leq 25.00^{\circ}$, a total of 11265 reflections were collected, of which 3731 were unique $\left(R_{\text {int }}=0.0230\right)$ and 3195 observed ones $(\mathrm{I}>2 \sigma(\mathrm{I}))$ were used in the succeeding structure calculations. Data collection and reduction were performed using the APEX II software ${ }^{14}$. Multiscan absorption corrections were applied using the SAINT $^{15}$. The structure was solved by direct methods and refined on $\mathrm{F}^{2}$ by full-matrix least squares technique using the SHELX-97 program package ${ }^{16,17}$. All non-hydrogen atoms were refined anisotropically. Hydrogen atoms attached to carbon were placed in geometrically idealized positions and refined using a riding model. Water $\mathrm{H}$ atoms were tentatively located in difference Fourier maps and were refined with distance restraints of $\mathrm{O}-\mathrm{H}$ $0.0842 \mathrm{~nm}$ and $\mathrm{HH} 0.138 \mathrm{~nm}$, with an standard deviation of $0.001 \mathrm{~nm}$ and with $\operatorname{Uiso}(\mathrm{H})=1.5 \mathrm{Ueq}(\mathrm{O}) . \mathrm{R}_{1}=0.0313$ and $\mathrm{wR}_{2}=0.0796\left(\mathrm{w}=1 /\left[\sigma^{2}\left(\mathrm{~F}_{0}^{2}\right)+(0.0432 \mathrm{P})^{2}+8.2553 \mathrm{P}\right], \mathrm{P}=\right.$ $\left(\mathrm{F}_{0}{ }^{2}+2 \mathrm{~F}_{\mathrm{C}}{ }^{2}\right) / 3$ for 3731 observed reflections with $\mathrm{I}>2 \sigma(\mathrm{I}) . \mathrm{S}=$

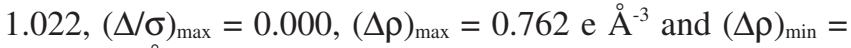
-0.728 e $\AA^{-3}$. Crystal parameters and details of the data collection and refinement are given in Table-1. Selected bond lengths and angles and H-bonding parameters are given in Tables 2 and 3, respectively.

\begin{tabular}{|c|c|c|c|}
\hline \multicolumn{4}{|c|}{$\begin{array}{c}\text { TABLE-2 } \\
\text { SELECTED BOND LENGTHS (̊̊) AND BOND ANGLES }\left(^{\circ}\right)\end{array}$} \\
\hline $\operatorname{Ag}(1)-\mathrm{N}(2) \# 1$ & $2.202(3)$ & $\operatorname{Ag}(1)-\mathrm{N}(1)$ & $2.219(2)$ \\
\hline $\mathrm{Ag}(1)-\mathrm{O}(1)$ & $2.561(2)$ & $\operatorname{Ag}(1)-\mathrm{O}(2)$ & $2.680(3)$ \\
\hline $\operatorname{Ag}(1)-\operatorname{Ag}(1) \# 2$ & $2.9603(7)$ & - & - \\
\hline $\mathrm{N}(2) \# 1-\operatorname{Ag}(1)-\mathrm{N}(1)$ & $154.54(9)$ & $\mathrm{N}(2) \# 1-\mathrm{Ag}(1)-\mathrm{O}(1)$ & $105.22(9)$ \\
\hline $\mathrm{N}(1)-\operatorname{Ag}(1)-\mathrm{O}(1)$ & $93.89(9)$ & $\mathrm{N}(2) \# 1-\mathrm{Ag}(1)-\mathrm{Ag}(1) \# 2$ & $86.47(7)$ \\
\hline$N(1)-A g(1)-A g(1) \# 2$ & $102.33(6)$ & $\mathrm{O}(1)-\operatorname{Ag}(1)-\operatorname{Ag}(1) \# 2$ & $111.23(6)$ \\
\hline
\end{tabular}

\section{RESULTS AND DISCUSSION}

Structure description: The X-Ray crystal structure of $\mathbf{1}$ contains silver atom, one 1,3-bis(4-pyridyl)-propane (bpp) and

\begin{tabular}{|ccccc}
\hline \multicolumn{6}{|c}{ TABLE-3 } \\
HYDROGEN BONDS FOR COMPLEX 1 \\
\hline $\mathrm{D}-\mathrm{H} \cdots \mathrm{A}$ & $\mathrm{d}(\mathrm{D}-\mathrm{H})$ & $\mathrm{d}(\mathrm{H} \ldots \mathrm{A})$ & $\mathrm{d}(\mathrm{D} \ldots \mathrm{A})$ & $<(\mathrm{DHA})$ \\
& $(\AA)$ & $(\AA)$ & $(\AA)$ & $\left({ }^{\circ}\right)$ \\
\hline $\mathrm{C}(2)-\mathrm{H}(2 \mathrm{~B}) \cdots \mathrm{Cl}(2)$ & 0.97 & 2.65 & $3.131(5)$ & 111.0 \\
$\mathrm{OW}-\mathrm{H}(1 \mathrm{OW}) \cdots \mathrm{O}(1) \# 4$ & $0.842(10)$ & $2.034(13)$ & $2.868(4)$ & $171(5)$ \\
$\mathrm{C}(10)-\mathrm{H}(10) \cdots \mathrm{O}(2) \# 2$ & 0.93 & 2.49 & $3.203(4)$ & 133.7 \\
\hline
\end{tabular}

Symmetry codes: \#2 -x+1, -y+1, -z \#4-x+1, y, -z+1/2.

one 2,6-dichlorophenylacetic acid ( $\left.\mathrm{dcpa}^{-}\right)$anions and one uncoordinated water molecule in the asymmetry unit, with the water molecule (OW) in special position. Each silver atom is coordinated to two nitrogens atom from two bpp ligand and two oxygen atom of the one $\mathrm{dcpa}^{-}$anion in the four-coordinate distorted tetrahedral configuration. The Hdcpa ligands are terminal and shows bidentate chelating modes[Ag-O 2.561(2) and 2.680(3) $\AA$ ] and the bpp ligand has adopted two end pyridyl $\mathrm{N}$ atoms that link to two Ag atoms [Ag-N 2.202(3) and 2.219(2) $\AA]$ (Scheme-I), the Ag1 and Ag $1{ }^{\text {ii }}$ distance is $2.960 \AA$, much shorter than van der Waals radii of two silver ions $(3.440 \AA)^{18}$ (Fig. 1 and Table-1).

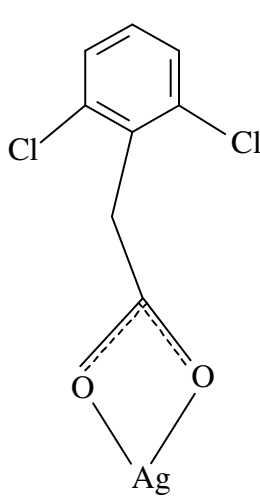

(a)

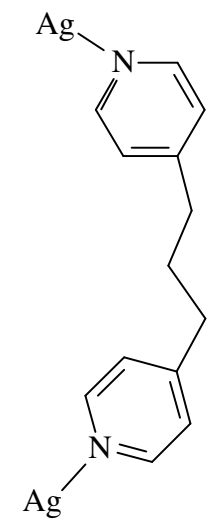

(b)
Scheme-I: Coordination mode of Hdcpa and bpp in complex $\mathbf{1}$

All the $\mathrm{Ag}(\mathrm{I})$ ions are surrounded by two nitrogen atoms from two bpp ligands form an in finite $[\mathrm{Ag}(\mathrm{bpp})]_{\mathrm{n}}$, adjacent Ag-bpp chains are linked into interesting two-dimensional, $\beta$-sheetlike layers by weak ligand-unsupported Ag...Ag contacts $^{19}$. The Ag1 ‥Ag1b distance separated by bpp ligand is $13.335 \AA$ and the bpp ligand has TG conformation (the two pyridyl groups of bpp ligand show different trans $(\mathrm{T})$ and gauche $(\mathrm{G})$ orientations) $)^{20}$ (Fig. 2). 


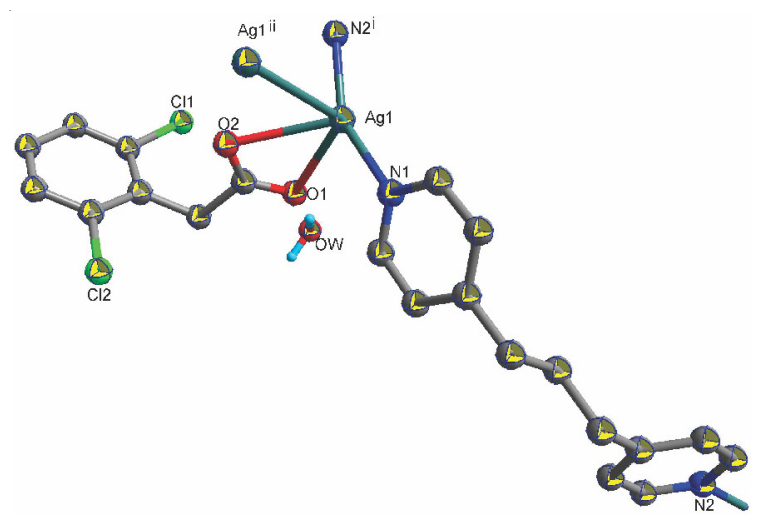

Fig. 1. View of the asymmetric unit of 1 with $30 \%$ probability ellipsoids. Symmetry codes $\mathrm{i}-1 / 2,-\mathrm{y}+1 / 2, \mathrm{z}-1 / 2 ;{ }^{\mathrm{ii}}-\mathrm{x}+1,-\mathrm{y}+1,-\mathrm{z}$

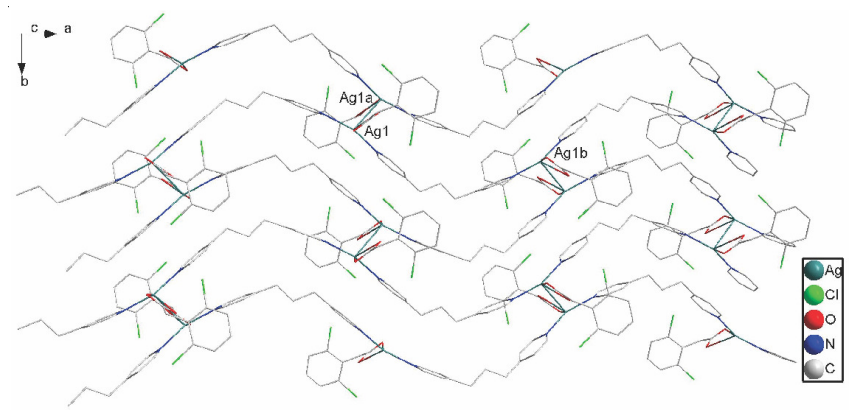

Fig. 2. $\beta$-Sheet like layers of the complex 1

The reverse arrangement of 2,6-dichlorophenylacetic acid $\left(\mathrm{dcpa}^{-}\right)$ligand layers on both sides. With the help of hydrogenbonded interactions between adjacent 2D sheet [OW$\mathrm{H}(1 \mathrm{OW}) \ldots \mathrm{O}(1)^{\mathrm{iv}}=2.034 \AA$, symmetry $\left.\operatorname{codes}^{\mathrm{iv}}-\mathrm{x}+1, \mathrm{y},-\mathrm{z}+1 / 2\right]$, the polymeric sheet are assembled to form a supramolecular 3-D network structure (Fig. 3 and Table-2).

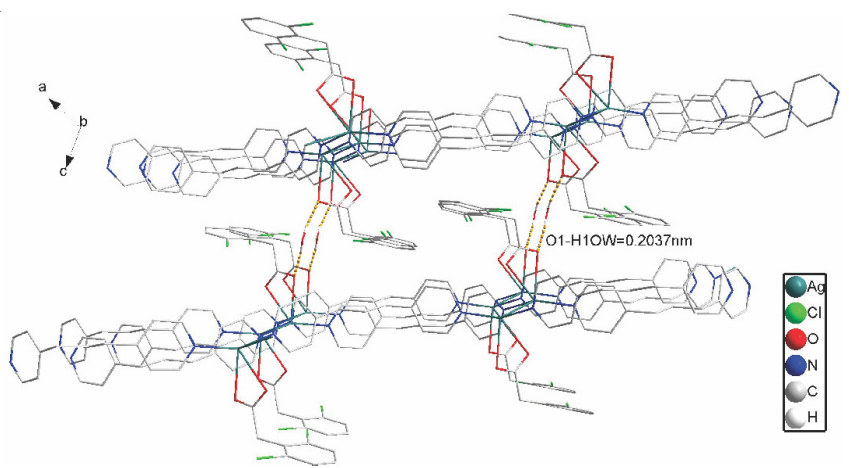

Fig. 3. A packing diagram for complex 1

IR spectrum: The IR spectrum of $\mathbf{1}$ clearly shows the presence of the Hdcpa and bpp. The absence of the absorption at $1691 \mathrm{~cm}^{-1}$ in the free Hdpa in $\mathbf{1}$ illustrates the complete deprotonation of the ligands in the reaction with $\mathrm{Ag}(\mathrm{I})$ ion. The strong bands at 1610 and $1435 \mathrm{~cm}^{-1}$ correspond to asymmetric $v_{\mathrm{as}}(\mathrm{COO})$ and symmetrical $\mathrm{v}_{\mathrm{s}}(\mathrm{COO})$ stretching vibrations, respectively of the coordinated carboxylate groups. In the compound 1 , The $\Delta v\left[v_{\text {as }}(\mathrm{COO})-v_{\mathrm{s}}(\mathrm{COO})\right]$ value is $175 \mathrm{~cm}^{-1}$. According to Nakamoto ${ }^{21}$, the carboxylate groups show bidentate-chelating coordination mode. Meanwhile, characteristic bands nearby $1527 \mathrm{~cm}^{-1}\left(1496 \mathrm{~cm}^{-1}\right.$ in 1) belong to the stretching vibration of $-\mathrm{N}=\mathrm{C}$ - of bpp ligands. The results of the IR spectra analyses of the complexes are in consistent with that of single-crystal X-ray analyses.

Thermal analysis: The thermal stability and thermal decomposition behavior of compound were studied by thermal analysis in a static $\mathrm{N}_{2}$ atmosphere in the temperature range $30-800{ }^{\circ} \mathrm{C}$ (Fig. 4). The first corresponding to the escape of one free water molecule is observed from $105-181^{\circ} \mathrm{C}$ (Obsd. $4.20 \%$, calcd. $3.46 \%$ ). The second corresponding to the escape of dcpa ${ }^{-}$and bpp ligands is observed from $181-274{ }^{\circ} \mathrm{C}$ (Obsd. $70.09 \%$, calcd. $69.80 \%$ ). Thermogravimetric curve displays the most weight loss of $7.49 \%$ from $274-408^{\circ} \mathrm{C}$, corresponding to the decomposition of the complex on the cards to form silver oxide. On further heating, the final decomposition product is metallic silver, with a total weight loss of $20.59 \%$.

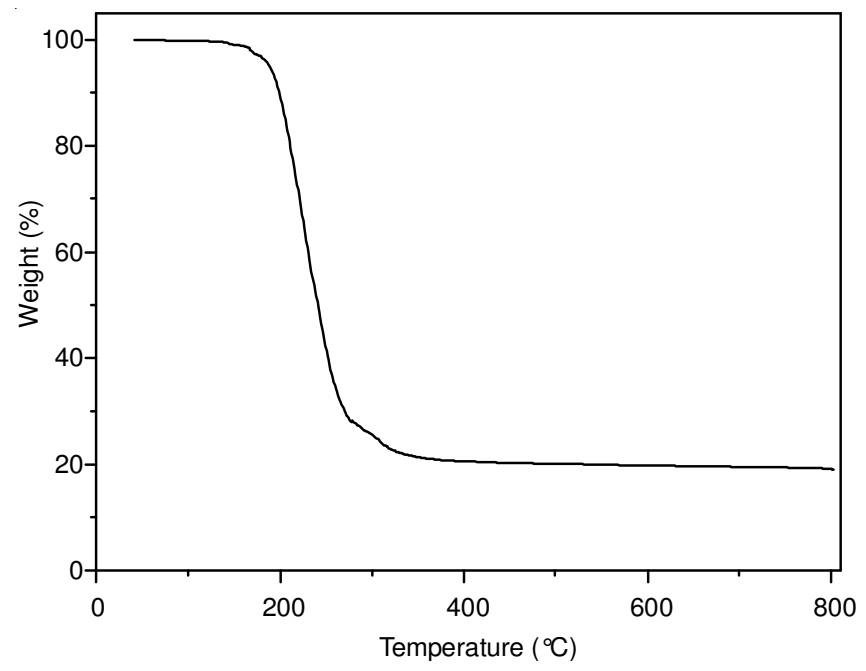

Fig. 4. Thermogravimetric curve of the complex $\mathbf{1}$

Photoluminescence properties: Coordination polymers based on $d^{10}$ metal centers and organic ligands are promising candidates for photoactive materials with potential applications $^{22}$. In this study, fluorescent property of compound has been investigated in the solid state. The emission peaks were not observed for free Hdcpa ligands. The emission peaks at ca. $455 \mathrm{~nm}\left(\lambda_{\mathrm{ex}}=372 \mathrm{~nm}\right)^{23}$ were observed for free bpp ligands. The emission bands for free ligands are probably attributed to the $\pi \rightarrow \mathrm{n}$ or $\pi^{*} \rightarrow \pi$ transitions. In the complex, strong fluorescence with emission peak at about $503 \mathrm{~nm}\left(\lambda_{\mathrm{ex}}=289 \mathrm{~nm}\right)$ was observed at room temperature (Fig. 5) and the emissions arising from the free ligands are not observed. This feature is due to energy transfer from the ligands to the $\operatorname{Ag}(\mathrm{I})$ atoms during photoluminescence. Therefore, the photoluminescence can probably be assigned to the ligandto-metal charge-transfer transitions ${ }^{24}$.

\section{Conclusion}

A new 2D silver (I) complex based on Hdcpa and bbp ligands, $\left\{[\mathrm{Ag}(\mathrm{bpp})(\mathrm{dcpa})] \mathrm{H}_{2} \mathrm{O}\right\}_{\mathrm{n}}$, has been synthesized and structurally characterized. This successful preparation of the title compound indicates that the bbp can be an excellent candidate for the construction of supramolecular complexes. Complex 1 emits the intensely luminescence with the fluorescence of $503 \mathrm{~nm}$ in the solid state at room temperature. 


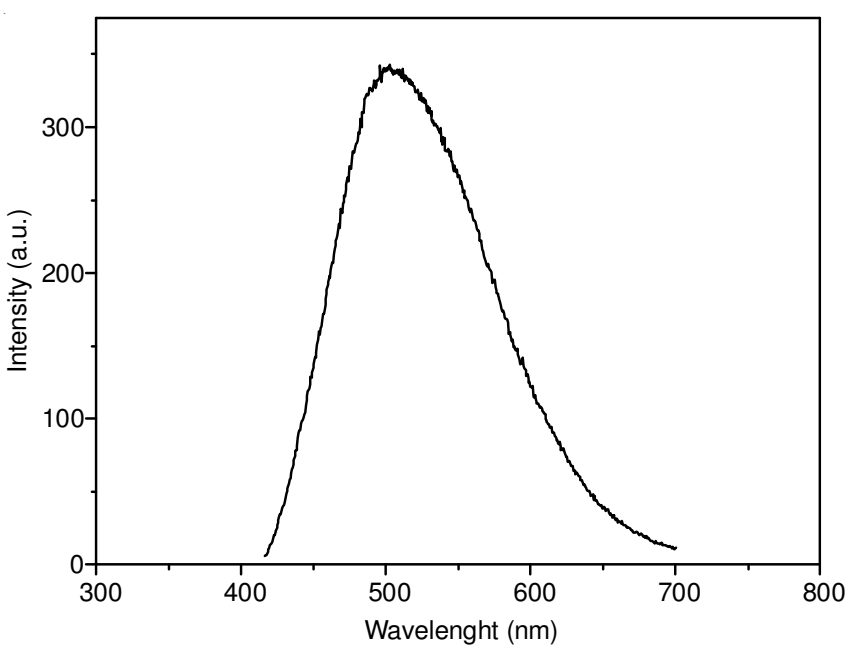

Fig. 5. Solid-state photoluminescent spectrum of complex $\mathbf{1}$

\section{ACKNOWLEDGEMENTS}

This research was financially supported by the Foundation of Guangdong Province (No. 2011B090400415), Foundation of zhanjian city (No. 2011C3108001) and National Natural Science Foundation of China (No. 21271055).

\section{REFERENCES}

1. A.U. Czaja, N. Trukhan and U. Müller, Chem. Soc. Rev., 38, 1284 (2009).

2. J.J. Perry IV, J.A. Perman and M.J. Zaworotko, Chem. Soc. Rev., 38, 1400 (2009)

3. Z.Q. Jiang, G.Y. Jiang, F. Wang, Z. Zhao and J. Zhang, Chem. Commun. (Camb.), 48, 3653 (2012).

4. N. Stock and S. Biswas, Chem. Rev., 112, 933 (2012).
5. D. Sun, L.L. Han, S. Yuan, Y.K. Deng, M.Z. Xu and D.F. Sun, Cryst. Growth Des., 13, 377 (2013)

6. J.K. Xu, X.C. Sun, Y.H. Fan, C.F. Bi and M. Sun, Z. Anorg. Allg. Chem., 638, 1512 (2012)

7. S.-S. Chen, Y. Zhao, J. Fan, T. Okamura, Z.-S. Bai, Z.-H. Chen and W.-Y. Sun, Cryst. Eng. Commun., 14, 3564 (2012).

8. L.Q. Fan, J.H. Wu, J.M. Lin and Y.F. Huang, Chin. J. Struct. Chem., 24, 1489 (2010).

9. S.M. Chen, J. Zhang and C.Z. Lu, Cryst. Eng. Commun., 9, 390 (2007).

10. P.K. Chen, Y.X. Che, L. Xue and J.M. Zheng, Cryst. Growth Des., 6, 2517 (2006).

11. P.B. Pan, X. Zhang, J.X. Yang, P.X. Yin and Y.G. Yao, Chin. J. Struct. Chem., 30, 1557 (2011).

12. L. Wen, H.D. Yin, W.K. Li and D.Q. Wang, Inorg. Chim. Acta, 363, 676 (2010).

13. J.L. Xue and C.H. Tian, Chinese J. Inorg. Chem., 30, 907 (2014).

14. Bruker, APEX II Software, Version 6.3.1, Bruker AXS Inc, Madison, Wisconsin, USA (2004).

15. Bruker, SAINT and SMART, Bruker AXS Inc., Madison, Wisconsin, USA (2004).

16. G.M. Sheldrick, SHELXS-97, Program for Crystal Structure Solution, University of Gottingen, Germany (1997).

17. G.M. Sheldrick, SHELXL-97, Program for the Refinement of Crystal Structure, University of Gottingen, Germany (1997).

18. M.L. Tong, Y.M. Wu, J. Ru, X.M. Chen, H.C. Chang and S. Kitagawa, Inorg. Chem., 41, 4846 (2002).

19. H.Q. Hao, W.T. Liu, W. Tan, Z.J. Lin and M.L. Tong, Cryst. Growth Des., 9, 457 (2009).

20. M.V. Marinho, M.I. Yoshida, K.J. Guedes, K. Krambrock, A.J. Bortoluzzi, M. Hörner, F.C. Machado and W.M. Teles, Inorg. Chem., 43, 1539 (2004).

21. K. Nakamoto, Infrared Spectra and Raman Spectra of Inorganic and Coordination Compound, Wiley, New York (1986).

22. S.L. Zheng and X.M. Chen, Aust. J. Chem., 57, 703 (2004).

23. Q.Y. Liu and L. Xu, Cryst. Eng. Commun., 7, 87 (2005).

24. S. Kitagawa, R. Kitaura and S. Noro, Angew. Chem. Int. Ed., 43, 2334 (2004). 